\title{
Truth Breakers
}

\author{
Dale Jacquette
}

Published online: 7 January 2010

(C) Springer Science+Business Media B.V. 2010

\begin{abstract}
Philosophical semantics requires an ontology that includes negative as well as positive states of affairs as truth-makers and truth-breakers. Theories that try to do without negative states of affairs while interpreting propositional truth as positive correspondence with existent states of affairs are inherently inadequate and incomplete. A semantics and ontology of negative states of affairs can also do justice to positive states of affairs, since the iterated negative state of affairs that a negative state of affairs exists describes a positive state of affairs, but the iterated positive state of affairs that a positive state of affairs exists never describes a negative state of affairs. Negative states of affairs are not only essential to semantics, but to a complete description of the world; they include phenomena of presence in absence and the metaphysics of gaps, lacks, holes and interstitia. The conceivability of an empty or null universe as consisting of nothing but negative states of affairs recalls a famous problem of Parmenides.
\end{abstract}

Keywords Parmenides - Positive, negative states of affairs · Semantics · Truth-breaker · Truth-maker

\section{Truth and its Makers}

A main task of philosophical semantics is to account for the truth-values of true or false sentences. The truth or falsehood of a sentence is determined by its truth conditions,

D. Jacquette $(\bowtie)$

Lehrstuhl ordentlicher Professur für Philosophie, Institut für Philosophie, Lehrstuhl für theoretische Philosophie, Unitobler, Universität Bern, Länggassstrasse 49a, 3000 Bern 9, Switzerland e-mail: dale.jacquette@philo.unibe.ch which are standardly said to depend at some depth of semantic analysis on the existence of the facts or states of affairs the sentence expresses. The truth of an affirmative proposition is established by the corresponding state of affairs the proposition represents, and that is accordingly said to be the proposition's truth-maker. Thus, the sentence, 'The watch is on the table', is made true by the state of affairs in which the watch is in fact on the table.

Philosophers as diverse in other aspects of their thinking as Aristotle, Gottlob Frege, Bertrand Russell, G. E. Moore, Carl Stumpf, Edmund Husserl, Ludwig Wittgenstein, Alfred Tarski, Rudolf Carnap, Roderick M. Chisholm, Donald Davidson, Robert Stalnaker, David Lewis, and David Armstrong, to name but a few prominent examples, have adopted an ontology of existent states of affairs as truth conditions for the semantics of propositional meaning, and, in particular, as the truthmakers of true sentences, statements, or propositions. The meaning of a sentence for these theorists is related in different ways to its truth conditions, which are generally understood as positive correlations with existent facts or states of affairs. ${ }^{1}$

The falsehood of an affirmative proposition, on the other hand, or, equivalently, the truth of its negation, is another matter. Truth-maker theories, for a variety of interesting reasons, as a rule have not taken sufficient notice of the problems connected with what in parallel fashion might be called truth-breakers as ontic conditions of a sentence's

\footnotetext{
${ }^{1}$ In lieu of listing out references to thinkers who have accepted an ontology of states of affairs as semantic truth-makers, I refer to a particularly articulate representative of this position in D. $M$. Armstrong, A World of States of Affairs (Cambridge: Cambridge University Press, 1997), especially pp. 13-14; 115-119; 128-135.
} 
falsehood, or, equivalently, again, as the truth-makers of its negation. ${ }^{2}$ What makes it false that 'The watch is on the table', when as a matter of fact the watch is not on the table? What makes it true that 'It is not the case that the watch is on the table' or that 'The watch is not on the table'? How much work can we expect a standard truthmaker semantics to do? Can it handle the workload, or must it be supplemented by additions to or refinements of stock truth-maker theories?

There seems to be a widespread but largely unspoken, unexamined and unargued assumption that if we take care of the truth conditions of true sentences, then we will have automatically taken care of the falsity conditions of false sentences. The negation of a false sentence, after all, is (classically anyway) a true sentence. If we have in hand a correct grasp of general semantic truth conditions for true sentences, then what difference does it make whether the sentences in question are logically or grammatically affirmations or negations? Although this seems a reasonable stance to adopt in developing a minimalist approach to truth-value analysis, we shall see that things are not so straightforward in understanding the logic, semantics, and metaphysics of falsehood and negation as mere extensions of those deemed adequate for truth and affirmation. We can begin to raise difficulties for an ontology and semantics of truth-breakers by asking what makes it false that the watch is on the table, if in fact the watch is not on the table. Is it a particular state of affairs or any of a range of states of affairs excluding those in which the watch is on the table? Or, if we are ideologically prepared to countenance negative states of affairs, might we say instead that what makes the sentence false when it is false is the lack, nonoccurrence, nonexistence, or failure to obtain of a particular state of affairs? What are the possibilities, and what are the advantages and disadvantages of these alternatives in working out a semantics of false predication?

In what follows, I explore the limitations of positive states of affairs as truth-breakers for false sentences. If the argument is correct, then negative states of affairs in the above sense are indispensable to the metaphysics of a correct philosophical semantics. To the extent that received theories of truth-makers rely exclusively on the existence of positive states of affairs as a reflection of the desire to

\footnotetext{
2 The trend is evident in Kevin Mulligan, Peter Simons and Barry Smith, 'Truth-Makers', Philosophy and Phenomenological Research, 44,1984 , pp. 287-321, where no provision for false sentences or the truth-breakers of false sentences is made. Notable exceptions include Bertrand Russell's 1917-1918 'Lectures on Logical Atomism', published as The Philosophy of Logical Atomism, edited by David Pears (LaSalle: Open Court Publishing, 1985), especially pp. 74-79. Russell, however, p. 79, declines in discussion at the lectures to offer a definition of 'negative facts', on the grounds that 'negativeness is an ultimate'. See also Richard Gale, Negation and Non-Being, American Philosophical Quarterly Monographs, 10, 1976.
}

scale down ontic commitments in accord with the principle of ontological parsimony, the demonstrated need for at least some negative states of affairs supports the inclusion of negative as well as positive states of affairs. Accordingly, I briefly sketch and develop some parts of a hybrid theory of positive and negative states of affairs as truthmakers and truth-breakers.

\section{States of Affairs, Positive and Negative}

We are naturally inclined, some would say overwhelmingly compelled, to think of ontology and philosophical semantics in positive terms. The world by reference to which the meaning and truth of many and arguably the most important episodes of thought and their expression in language are determined is something extant. It is the existent world that gives us something to talk about, and there could hardly be language users or concrete language tokens were it not for the positive states of affairs that constitute the actual world. The emphasis on positive states of affairs, on facts or moments that exist, occur, or obtain, on what is present or manifest rather than what is absent or fails to exist, is understandable if not inevitable or ultimately justifiable. Unsurprisingly, standard issue extensionalist ontology and semantics focus exclusively on positive states of affairs as truth-makers for true sentences.

Let us proceed by defining and distinguishing more precisely the ontic categories of positive and negative states of affairs.

A state of affairs, generally, is either positive or negative.

A positive state of affairs is an object's possession of a property, or its participation in a relation. (Example: The sky's being blue; the watch's being on the table.)

A negative state of affairs is the failure of an object to possess a property, or its nonparticipation in a relation. (Example: The sky's not being blue; the watch's not being on the table.)

The existence of a negative state of affairs is the same thing as the nonexistence of a corresponding positive state of affairs. A semantic theory that attempts to account for the truth-values of certain sentences by referring ostensibly to the existence or nonexistence of positive states of affairs only on the above definition is, perhaps despite itself, committed to an interface of ontology and semantics that includes at least some negative states of affairs. We can therefore think of a false sentence's truth-breaker as the truth-maker of its negation.

One method of criticizing a truth-maker theory in light of these considerations is to compare the prospects and limitations of a general ontic-semantic theory schema that 
invokes positive states of affairs only as both truth-makers and truth-breakers with those of rival theories that countenance negative states of affairs. The following array covers all possible combinations. We can have true or false affirmative or negative sentences. We must therefore ask whether and how an ontic-semantic theory limited exclusively to positive states of affairs can provide the needed truth-makers and truth-breakers for each of these four semantic categories.

Theory 1: Positive States of Affairs as Truth-Makers and Truth-Breakers.

1. Positive state of affairs as truth-maker for true affirmative sentence: The sentence, 'The watch is on the table', is made true if and only if the positive state of affairs in which the watch is on the table exists.

2. Positive state of affairs as truth-breaker for false negative sentence: The sentence, 'The watch is not on the table' ('It is not the case that the watch is on the table'), is made false if and only if the positive state of affairs in which the watch is on the table exists.

3. Positive state of affairs as truth-breaker for false affirmative sentence: The sentence, 'The watch is on the table', is made false if and only if the positive state of affairs in which exists.

4. Positive state of affairs as truth-maker for true negative sentence: The sentence, 'The watch is not on the table' ('It is not the case that the watch is on the table'), is made true if and only if the positive state of affairs in which exists.

The challenge here is to fill in the blanks in schemata (3) and (4) with the description of a purely positive state of affairs that serves as a truth-breaker for the sentence, 'The watch is on the table', when in fact there is no watch on the table, and as a truth-maker for the true negative sentence, 'The watch is not on the table' ('It is not the case that the watch is on the table'), when again there is in fact no watch on the table. What sorts of solutions might be proposed?

We might first attempt to describe the state of affairs in which the table contains other things, none of which is a watch, or in which the table top is completely described without mention of a watch, adding that what has been positively described (sans watch) is the totality of objects on the table. Wittgenstein gets away with something like this reduction of negative to positive states of affairs in the Tractatus, but only with respect to the existence or nonexistence of specifically atomic or logically simplest facts (Sachverhalte, in the technical sense of the term Wittgenstein develops there) composing the basic structure in logical space for the more complex facts recognized by common sense and rigorous science. Any one of the Tractatus atomic facts can either be the case or not be the case, he maintains, while everything else remains the same. ${ }^{3}$ In contrast, we are speaking here about the semantic role of complex facts as truth-makers or truth-breakers, where the situation is very different. It is true that the above-mentioned ways of characterizing the watch-less table top explicitly refer to negative states of affairs-'none of which is a watch'; 'without mention of a watch'; 'sans watch'. These are formulated, however, so to speak, only meta-semantically. As such, they need not be included in the descriptions of states of affairs themselves concerning the watch-less or sans-watch table top by which we try to complete the schemata blanks with descriptions of purely positive states of affairs that characterize the table as deprived of watches.

Suppose we describe the table top in purely positive terms, in which no watches are mentioned, and we add that, concerning whatever objects if any are on the table, perhaps a teacup and paperweight, that these are the totality or all and only the objects located there. Can such a description of purely positive states of affairs constitute a truth-breaker for the sentence, 'The watch is on the table', when in fact there is no watch on the table? Can it constitute a truth-maker for the sentence, 'The watch is not on the table', when in fact there is no watch on the table? There would appear to be only two possibilities, neither of which provides an adequate truthbreaker for the false affirmative sentence or truth-maker for the true negative sentence. What we need is to be able to derive whatever is minimally required, logically or extralogically, from the complete description of the table top offered exclusively in terms of positive states of affairs as (meta-semantically) containing no watches in order to make false the false affirmative sentence, 'The watch is on the table', and to make true under the same circumstances the true negative sentence, 'The watch is not on the table'.

The first possibility is that the complete description of the watch-less table top logically implies that it is false that 'The watch is on the table' and true that 'The watch is not on the table'. The proposal requires that what is made true by the positive states of affairs that exist also determine what is thereby made false. Again, this works for Wittgenstein's atomic facts and the elementary propositions by which they are expressed, but not for complex facts belonging to complex supervenience nets of ontic dependence. We need

\footnotetext{
${ }^{3}$ Ludwig Wittgenstein, Tractatus Logico-Philosophicus, edited by C.K. Ogden (London: Routledge \& Kegan Paul Ltd., 1922), '1.11 The world is determined by the facts, and by these being all the facts. 1.12 For the totality of facts determines both what is the case, and also all that is not the case. 2.04 The totality of existent atomic facts is the world. 2.05 The totality of existent atomic facts also determines which atomic facts do not exist. 2.06 The existence and non-existence of atomic facts is the reality. (The existence of atomic facts we also call a positive fact, their non-existence a negative fact.)'
} 
under this first stratagem to be able validly to infer that it is not the case that the watch is on the table from the description of whatever is on the table together with the fact that this is the totality of or that these are all and only the things on the table. Can this be done entirely without reference to any negative states of affairs? There are two obstacles. The reasoning is formally invalid, unless we include the fact that any of the objects mentioned as being on the table top is not a watch, thus bringing another negative fact into the inference. The logic has this form:

1. The teacup is on the table.

2. The paperweight is on the table.

3. The teacup and the paperweight are the only things on the table.

4. It is false that the watch is on the table.

A second problem is that despite superficial appearances, proposition (3) describes a negative state of affairs. For it is logically equivalent to the explicitly negative existential: 'There is nothing on the table other than the teacup and the paperweight'. This, we might say, is its meaning, without which the effect of providing the necessary truth-breaker or truth-maker is not assured. The sentence in (3) as a result requires a negative state of affairs as its truth-maker after all; it does not in that case meet its logical-semantic explanatory burden by appealing exclusively to purely positive states of affairs.

We may be more accustomed to thinking of totality, of all and only, as a positive state of affairs. As reflection shows, the question is more complicated. The standard formulations by which totalities are described are at least superficially grammatically affirmative rather than negative. Thus, we say, after listing the items located on a table top, that these are all of the objects situated there, that this is the total inventory. If the list contains only the items 'teacup' (c) and 'paperweight' (p), then we can say of things on $(\mathrm{O})$ the tabletop (t) minus the watch (w), that:

$\mathrm{O}(\mathrm{t}, \mathrm{c}) \wedge \mathrm{O}(\mathrm{t}, \mathrm{p}) \wedge \forall \mathrm{x}[\mathrm{O}(\mathrm{t}, \mathrm{x}) \rightarrow[\mathrm{x}=\mathrm{c} \vee \mathrm{x}=\mathrm{p}]]$

The universal clause expresses the fact that the totality of objects on the table top is limited to the teacup and paperweight; thus, in effect, excluding the watch. True enough, there is no explicit use of negation in proposition (1). Shall we then be satisfied with (1) as an interpretation involving no negative or nonexistent positive states of affairs?

The answer seems to be no. The conclusion is not logically guaranteed unless or until we specify that the watch is not identical to the teacup, or to the paperweight or table top. We must, then, if we are being perspicuous about the totality of objects on the table, include the following clause describing an ostensibly negative state of affairs, whereby:

$\forall \mathrm{x}[[[\mathrm{x}=\mathrm{c} \rightarrow \mathrm{x} \neq \mathrm{w}] \wedge[\mathrm{x}=\mathrm{p} \rightarrow \mathrm{x} \neq \mathrm{w}]] \wedge[\mathrm{x}=\mathrm{t} \rightarrow \mathrm{x} \neq \mathrm{w}]]$

Alternatively, with less fuss, we can also write:

$\mathrm{c} \neq \mathrm{w} \wedge \mathrm{p} \neq \mathrm{w} \wedge \mathrm{t} \neq \mathrm{w}$

These nonidentities are explicitly negative, and as such, in lieu of an adequate philosophical semantics limited exclusively to the existence of positive states of affairs, they presumably correspond to negative states of affairs as their truth-makers. By 'presumably' here I mean that at this point we have not yet found a clearcut way of eliminating them, as we might at first have hoped. We can simplify the conditions by avoiding the need to distinguish the table top from the watch if we maintain that nothing is on top of itself, by means of the general principle, $\forall \mathrm{x}[\neg \mathrm{O}(\mathrm{x}, \mathrm{x})]$ or $\forall \mathrm{x} \forall \mathrm{y}$ $[[\mathrm{O}(\mathrm{x}, \mathrm{y}) \vee \mathrm{O}(\mathrm{y}, \mathrm{x})] \rightarrow \mathrm{x} \neq \mathrm{y}]$. This condition explicitly introduces yet another negation presumably corresponding to yet another negative state of affairs as its truth-maker. The combined effect of these conditions is to alter the original affirmative totality statement to an expression containing several patently negative assertions, with something like the form:

$$
\begin{aligned}
& \mathrm{O}(\mathrm{t}, \mathrm{c}) \wedge \mathrm{O}(\mathrm{t}, \mathrm{p}) \wedge \forall \mathrm{x}[\mathrm{O}(\mathrm{t}, \mathrm{x}) \rightarrow[\mathrm{x}=\mathrm{c} \vee \mathrm{x}=\mathrm{p}]] \\
& \wedge \mathrm{c} \neq \mathrm{w} \wedge \mathrm{p} \neq \mathrm{w} \wedge \forall \mathrm{x}[\neg \mathrm{O}(\mathrm{x}, \mathrm{x})]
\end{aligned}
$$

The requirement so explicated makes it clear that the totality principle, while superficially positive, harbors hidden ineliminable negations for which negative states of affairs remain the best candidates as presumptive truthmakers. Although to say that a list contains the totality of items belonging to a certain category appears at first to be a positive state of affairs, what it means on reflection to say that a given specification of entities is the totality of such things is that all other things are excluded, which in the above sense is again presumably made true only by a negative state of affairs, in that anything else is not to be considered as belonging to the specified totality. To assert that $\mathrm{X}, \mathrm{Y}$, and $\mathrm{Z}$ are the totality of things belonging to category $\mathrm{C}$ is always to say that nothing else belongs to $\mathrm{C}$, and this is unmistakably to say something negative.

Another damaging objection to this first method of trying to acknowledge positive states of affairs as the only category of truth-makers and truth-breakers for true or false affirmative or negative sentences is that thus far at least there is no conceptual bridge to carry the inference from the assumptions to the conclusion. Logic by itself, considered only in and of itself, knows nothing of tables and watches, teacups or paperweights. As far as pure logic is concerned, 
all tables might already or analytically come equipped with watches on them, as part of the concept of a table, or of what it means for something to be a table, in roughly the same way that a table necessarily possesses at least one leg, a bachelor is necessarily an unmarried male adult, or something colored is necessarily extended. Nor does logic by itself rule out the possibility that 'teacup' or 'paperweight' might not be just another word for 'watch', in the way that (with appropriate qualifications) 'pocket or wrist clock' or 'timepiece' can refer to the same object. We cannot expect the assumptions in (1-3) of the inference above validly to imply the conclusion in (4), with or without the requirement for a negative state of affairs to provide the implicit truth-maker for assumption (3). It is an invalid inference independently of the need for a negative state of affairs, unless we add the bridge principle according to which, in effect, "A table does not analytically come equipped with a watch', and 'The words "teacup" and "paperweight" are not synonyms for "watch", nor does their existence imply or entail the existence of a watch', both of which take us back immediately to the problem of positing a negative state of affairs as truth-maker.

The failure of the bridge principle needed to validate the logical entailment of the truth-breaker for the sentence 'The watch is on the table', when in fact there is no watch on the table, also exposes the limitations of a second, extralogical, method of interpreting purely positive states of affairs as truth-breakers of false affirmative sentences and truthmakers of true negative sentences. The suggestion is that we establish a conceptual link between the condition of the table top when it (meta-semantically speaking) lacks the presence of a watch, in positive terms only of the things it does contain, such that it follows as a truth-breaker by which the sentence, 'The watch is on the table' is made false, and as a truth-maker for the negative sentence, 'The watch is not on the table'. The difficulty encountered in the extralogical proposal is precisely the same as that involved in the second strategy for making the purely logical implication proposal work. We should recognize that in order to construe the positive states of affairs that constitute the watch-less table top as a truth-breaker for the sentence, 'The watch is on the table', when in fact the sentence is false (or as a truth-maker for the negative sentence, 'The watch is not on the table'), we need to appeal to extralogical principles concerning the fact that there are no other objects on the table, that 'watch' is not another word for a teacup or paperweight, that tables do not analytically come equipped with watches, or the like. The problem as before is that all such information must apparently be conveyed by sentences whose truth-makers apparently can only be negative states of affairs.

Where affirmative sentences alone are concerned, we do not need and cannot plausibly invoke negative states of affairs as truth-makers. The semantic requirements of truthbreakers for affirmative sentences, however, are another story. There, it seems, we have no choice but to admit negative states of affairs alongside positive states of affairs.

\section{Negative States of Affairs as Truth-Makers and Truth-Breakers}

We should accordingly consider the principles of an onticsemantic theory that incorporates negative states of affairs as truth-makers and truth-breakers.

Theory 2: Hybrid Positive-Negative States of Affairs as Truth-Makers and Truth-Breakers.

1. Positive state of affairs as truth-maker for true affirmative sentence: The sentence, 'The watch is on the table', is made true if and only if the positive state of affairs in which the watch is on the table exists.

2. Positive state of affairs as truth-breaker for false negative sentence: The sentence, 'The watch is not on the table' ('It is not the case that the watch is on the table'), is made false if and only if the positive state of affairs in which the watch is on the table exists.

3. Negative state of affairs as truth-breaker for false affirmative sentence: The sentence, 'The watch is on the table', is made false if and only if the negative state of affairs in which it is not the case that the watch is on the table exists.

4. Negative state of affairs as truth-maker for true negative sentence: The sentence, 'The watch is not on the table', is made true if and only if the negative state of affairs in which it is not the case that the watch is on the table exists.

An ontology that includes negative states of affairs provides a straightforward semantic analysis of propositional negation. The truth conditions for a proposition, a declarative true or false sentence, establish a correspondence between the sentence and a state of affairs, positive or negative, that makes the sentence true or that makes it false. Semantics considered formally is a matter of abstract mapping relations relating language and the world, names and a domain of objects, or the like. Negation is a relative concept, since we can equally say that 'The watch is on the table' is the negation of 'The watch is not on the table', just as we can say that 'The watch is not on the table' is the negation of 'The watch is on the table'. Each is the negation of the other, indicating that negation, unsurprisingly, is nothing positive in itself. We can formalize the ontic-semantic principles that we have informally defended in these terms:

$\forall \mathrm{x}, \mathrm{p}[[\operatorname{Truth}-\operatorname{maker}(\mathrm{x}, \mathrm{p}) \vee$ Truth-breaker $(\mathrm{x}, \mathrm{p})] \rightarrow \mathrm{E} ! \mathrm{x}]$

We require, as previously informally explained, that a state of affairs, positive or negative, must exist in order to 
be a truth-maker or truth-breaker of any proposition, atomic or compound.

$\forall \mathrm{x}, \mathrm{p}[\operatorname{Truth}-\operatorname{maker}(\mathrm{x}, \mathrm{p}) \leftrightarrow$ Truth-breaker $(\mathrm{x}, \neg \mathrm{p})]$

The principle stipulates that a state of affairs is a truthmaker for a given affirmative sentence if and only if the same state of affairs is a truth-breaker for the sentence's negation. It follows by uniform substitution that a state of affairs is a truth-maker for a given negative sentence if and only if it is also the truth-breaker for the corresponding affirmative sentence:

$\forall \mathrm{x}, \mathrm{p}[$ Truth-maker $(\mathrm{x}, \neg \mathrm{p}) \leftrightarrow$ Truth-breaker $(\mathrm{x}, \mathrm{p})]$

An implication of (P2) and (P3), in accord with the proposed analysis of truth, falsehood, affirmation, negation, and positive and negative states of affairs as truth-makers and truth-breakers, is that there is no simple correlation between negation and truth-breakers. The same positive or negative state of affairs can alternatively be a truth-maker or truth-breaker, depending on the nature of the case and the prevailing truth-making or truth-breaking circumstances in the world. If a positive state of affairs is the truth-maker for a given affirmative sentence, however, then it is certain that the sentence's truth-breaker, and the truth-maker of its negation, will be a negative state of affairs. ${ }^{4}$

\footnotetext{
${ }^{4}$ Purely for theoretical interest, it is worth noting that it is possible to advance a reductive account of truth-makers and truth-breakers for true and false affirmative and negative sentences. Whereas we cannot get by exclusively with positive states of affairs as truth-makers and truth-breakers, we can contrariwise meet the semantic obligations in question with only negative states of affairs. The reason for the asymmetry is clear when we reflect informally that two positives do not make a negative, but two negatives make a positive.
}

Theory 3 (Reduction):

Negative States of Affairs as Truth-Makers and Truth-Breakers

1. Negative state of affairs as truth-maker for true affirmative sentence: The sentence, 'The watch is on the table', is made true if and only if the negative state of affairs in which it is not the case that the watch is on the table fails to exist.

2. Negative state of affairs as truth-breaker for false negative sentence: The sentence, 'The watch is not on the table', is made false if and only if the negative state of affairs in which it is not the case that the watch is on the table exists.

3. Negative state of affairs as truth-breaker for false affirmative sentence: The sentence, 'The watch is on the table', is made false if and only if the negative state of affairs in which it is not the case that the watch is on the table exists.

4. Negative state of affairs as truth-maker for true negative sentence: The sentence, 'The watch is not on the table', is made true if and only if the negative state of affairs in which it is not the case that the watch is on the table exists.

The distinction is manifest among other ways in symbolic logic by the fact that all of the five standard propositional connectives can be reduced to any of the remaining three plus negation, even if combined in a single operator like the Sheffer stroke or Nicod dagger function, but that without negation, or at least predicate complementarity in the
We further observe that if the truth-maker of a sentence is a positive state of affairs, then the sentence's truth-breaker will be the corresponding negative state of affairs. The latter can also be characterized as the negation of a description of the corresponding positive state of affairs, and hence of whatever predication of property or relations to an object or ordered set of objects constitutes the relevant positive state of affairs. For simplicity and merely heuristically, we consider all relations reductively as relational qualities. Thus, the relation Rab via lamba abstraction becomes alternatively (and indifferently) the unary predication $\lambda x[R x b] a$ or $\lambda x[\operatorname{Rax}] b$. For any proposition $\mathrm{p}$, we represent the state of affairs such that $\mathrm{p}$ by enclosing ' $\mathrm{p}$ ' within wedge brackets, as $<\mathrm{p}>$. More formally, then, we can say:

$$
\begin{aligned}
& \forall \mathrm{x}, \mathrm{y}, \mathrm{p}[[\text { Truth-maker }(\mathrm{x}, \mathrm{p}) \wedge \mathrm{x}=\langle\phi \alpha>] \\
& \leftrightarrow[\text { Truth-breaker }(\mathrm{y}, \mathrm{p}) \leftrightarrow \mathrm{y}=\langle\neg \phi \alpha>]]
\end{aligned}
$$

Here the clear implication is that negative states of affairs, as truth-makers or truth-breakers, do not informatively explicate but rather presuppose the concept of negation. Such a result is preapparent in the phrase, 'negative state of affairs'. It is nevertheless well worth emphasizing the fact because there is a strong temptation to consider the ontic status of truth-breakers as something grounding the concept of negation. An adequate ontic-semantic theory of truth conditions for affirmative and negative sentences as a result must acknowledge the complementary existence of positive states of affairs as truth-makers for affirmative predications, and of truth-breaking negative states of affairs as the nonexistence of corresponding truth-makers. The nonexistence of a state of affairs as a negative state of affairs once again presupposes rather than helps to explicate the concept of negation, which in semantics as in propositional logic appears to be a primitive logical relation.

$$
\begin{aligned}
\forall \mathrm{x}, \mathrm{y}, \mathrm{p}[[\text { Truth-maker }(\mathrm{x}, \mathrm{p}) \wedge \mathrm{x} & =<\mathrm{E} ! \alpha>] \\
\leftrightarrow & \leftrightarrow \text { Truth-breaker }(\mathrm{y}, \mathrm{p}) \leftrightarrow \mathrm{y}=<\neg \mathrm{E} ! \alpha>]]
\end{aligned}
$$

The same is even more obviously true in the purely propositional counterpart of (P5), in which the existence or nonexistence of a truth-making or truth-breaking state of affairs is written finally in simplest form, where ' $p$ ' is an affirmative sentence such as an atomic wff (well-formed formula):

$$
\begin{aligned}
& \forall \mathrm{x}, \mathrm{p}[[\text { Truth-maker }(\mathrm{x}, \mathrm{p}) \rightarrow \mathrm{E} ! \mathrm{x}] \wedge[\text { Truth-breaker }(\mathrm{x}, \mathrm{p}) \\
& \quad \rightarrow \neg \mathrm{E} ! \mathrm{x}]]
\end{aligned}
$$

What if we try to say that a sentence is true iff it has a truth-maker, and is otherwise false? The lack of a

Footnote 4 continued

case of a Boolean algebra, there can be no adequate propositional logic. 
truth-maker makes the sentence false and is therefore constitutes its truth-breaker. This is correct as far as it goes, but it implies that in such a situation the sentence has no truth-maker, that the sentence's positive fact truth-maker fails to exist, where the truth-maker's nonexistence is once again a negative state of affairs as truth-maker.

Note that in (P6) we do not deny that a truth-breaker is an existent state of affairs. Rather, the principle asserts conditionally that if a certain state of affairs is a truthmaker for a given atomic proposition, then there exists no truth-breaker for the same atomic proposition. According to the present proposal, both truth-makers and truthbreakers are existent positive or negative states of affairs, but there exists no state of affairs that is both a truth-maker and truth-breaker for the same proposition. Intuitively, we know:

$\forall \mathrm{p}[\mathrm{E} !<\neg \mathrm{p}>\leftrightarrow \neg \mathrm{E} !<\mathrm{p}>]$

The notation thereby encourages us to speak of the existence even of states of affairs in which another state of affairs does not exist, when the nonexistence of a certain state of affairs itself exists as a truth-breaker for a given (atomic) proposition, as $\mathrm{E} !<\neg \mathrm{E} ! \alpha\rangle$. Further elaborations of the theory are possible, in which we stipulate for example that from $\neg \mathrm{E}$ ! $\langle\neg \mathrm{E}$ ! $\alpha\rangle$ we rightly infer that $<\neg \mathrm{E}$ ! $\alpha>$ can be a truth-maker or truth-breaker for any wff-even when $\alpha$ considered in itself provides either (but not both) a truth-maker or truth-breaker (not both) for a certain proposition. By contrast, from $\neg \mathrm{E}$ ! $\alpha$ we rightly infer that $\alpha$ cannot be either a truth-maker or truth-breaker for any wff, whereas $\neg E$ ! $\alpha$ under the same circumstances might be a truth-maker or a truth-breaker (but not both) for some proposition, provided that $\mathrm{E} !\langle\neg \mathrm{E} ! \alpha\rangle$. Iterations of existence assertions or denials for states of affairs as opposed to immediate reference to the corresponding states of affairs themselves are possible, but would appear to belong exclusively to the realm of ingenious philosophical thought experiments rather than to the minimally essential semantic requirements of truth-makers and truth-breakers in ordinary, including very complicated, but in this sense extra-philosophical, applications. Such iterations in any case do not threaten the semantic principles for truthmakers and truth-breakers of true or false affirmative and negative sentences.

The use of truth tables as matrices of truth-values ' $T$ ' and ' $F$ ' in the definition of propositional connectives including negation can now be explained. The ontic status of truth-values has frequently been left mysterious, or, as in Frege, arbitrarily assigned to abstract objects, 'the True' and 'the False'. This is clearly an undesirable lacuna and makeshift in the formal semantics of propositional logic. The proposed ontic-semantic framework of positive and negative states of affairs now permits us to interpret truth-values as representing the existence or nonexistence of corresponding truth-makers, which is to say, where atomic wffs are arrayed in the leftmost columns of a standard truth table, of positive states of affairs as truth-makers and negative states of affairs as truth-breakers, through which the truth-functional meanings of more complex wffs are determined. To write ' $\mathrm{T}$ ' below or beside a propositional symbol in a truth table can be understood in effect as indicating the existence of a corresponding positive state of affairs as truthmaker, or, equivalently, the nonexistence of a corresponding truth-breaking negative state of affairs. At the same time, writing ' $F$ ' indicates the nonexistence of a corresponding positive state of affairs as truth-maker, or equivalently the existence of a corresponding truth-breaking negative state of affairs. Since propositional symbols are always syntactically atomic, their truth-makers on the present account are necessarily positive states of affairs, and their truth-breakers, or the truth-makers of their negations, are necessarily negative states of affairs. A complete standard truth table is then a definition by cases of the truth conditions for the formally characterized wffs in a propositional logic. The truth conditions it displays represent the existence of truth-makers and truth-breakers for component atomic wffs or propositional symbols, which are, respectively, positive and negative states of affairs, codified in ontic-semantic principles (P1-P6).

We should accordingly disillusion ourselves, when we write out a bivalent truth table definition for propositional negation, that we are informatively defining the concept of negation, as though out of whole cloth. The truth table for negation does not define the concept of negation, as we may like to tell beginning symbolic logic students, but at most articulates one interpretation of a negation sign in a formalized bivalent propositional logic. For an array of truth-values informatively to define the concept of negation, it would need to introduce the concept for the first time, from the ground up. We have now seen that this cannot be the case in the standard truth table definition of negation. The meaning of the ' $T$ 's' and ' $F$ ' $s$ ' in terms of which the negation sign is defined instead presuppose the concept of negation. Where, simply put, ' $\mathrm{T}$ ' represents the existence of a propositional symbol's truth-maker, and ' $F$ ' represents the existence of its corresponding truth-breaker, the nonexistence of its truth-maker, it follows that truthmakers are distinguished from truth-breakers metasemantically, as explicated in (P1-P6), on the present interpretation, by means of a prior concept of negation that is already present and operative in, rather than defined from scratch by the meaningfulness of, a truth table definition of the negation sign. ${ }^{5}$

\footnotetext{
5 The same conclusion obviously holds with respect to nonclassical gap and higher-valued truth tables that transcend bivalence.
} 


\section{Presence in Absence}

The appeal to negative states of affairs is not merely ontically convenient, but indispensable for many purposes in philosophical semantics. Now that we have examined reasons for including negative states of affairs as truthmakers and truth-breakers in formal semantics, we turn to philosophical considerations about negative states of affairs in metaphysics and everyday reasoning.

What makes negative facts essential is the occurrence of something real albeit nonexistent that must be designated and described in order adequately to account for the state of the world. There is often something substantive about negative states of affairs. There seem to be truths about the world that can only be understood as something negative, something that is not there, missing, or absent, but that nevertheless possess a kind of presence in absence-as Jean-Paul Sartre in Being and Nothingness maintains of his normally punctual friend Pierre when he fails to appear as promised at the café at the appointed hour. It is negative facts such as these, like the watch not being on the table, that cannot be conveyed exclusively in terms of existent positive states of affairs. ${ }^{6}$

Consider as examples a non-reply to a letter. A colleague always answers mail in a short period of time until one sends a note critical of a book or article the person has recently published. One calls up one's e-mail or looks in the letter bin for days and weeks or even longer. The missing reply, the fact that no answer has been given, has a significance that cannot be adequately understood in positive terms of the correspondence one has received from which the colleague's communications are missing, together with any other ensemble of positive facts. Perhaps the colleague is miffed and is deliberately choosing not to respond to indicate displeasure. If so, then the negative state of affairs of the nonreply or failure of the colleague to reply is in its own way potentially even more eloquent than if the person had sent back an angry response or offered a conspicuous snub at a conference or social occasion as a

\footnotetext{
${ }^{6}$ Jean-Paul Sartre, Being and Nothingness: An Essay on Phenomenological Ontology, translated and with an introduction by Hazel Barnes (New York: Philosophical Library, 1956), p. 9: 'But if we wish to decide with certainty, we need only to consider an example of a negative judgment and to ask ourselves whether it causes non-being to appear at the heart of being or merely limits itself to determining a prior revelation. I have an appointment with Pierre at four o'clock. I arrive at the café a quarter of an hour late. Pierre is always punctual. Will he have waited for me? I look at the room, the patrons, and I say, "He is not here." Is there an intuition of Pierre's absence, or does negation indeed enter in only with judgment? At first it seems absurd to speak of intuition since to be exact there could not be an intuition of nothing and since the absence of Pierre is this nothing. Popular consciousness, however, bears witness to this intuition. Do we not say, for example, "I suddenly saw that he was not there." Is this just a matter of misplacing the negation?' See also pp. 9-16 and passim.
}

clearcut positive state of affairs. The fact that we expect a reply and do not receive one under the circumstances makes its non-receipt as real a part of the world as a nasty rejoinder; yet it has its own special character, an aura of ambiguity inspiring doubt, and of causing one to worry and think about the effect of one's actions that may have occasioned the failure to respond. It is a negative state of affairs that is as real to a complete description of the situation as any relevant positive fact of the matter.

Once we become sensitized to the importance of negative states of affairs we may begin to see their presence in absence in many different contexts. Every year we spend the holidays with relatives sitting around the table where grandpa tells stories about his wild oats days in Montmartre, until one year he passes away and things are patently no longer the same. We gather at table and there conspicuously is grandpa's empty chair. We can almost hear him starting up one of his implausible tales and making jokes, being the life of the party. He is gone, and the negative state of affairs of his not being there is as palpably real a fact about the family dynamic as any of the positive states of affairs that happen to obtain. Nor can we account for his absence and the difference his absence makes by specifying that he was there the previous year and said this and that, and that this year the company consisted of other persons who had this and that to eat and this and that to say. There is something more to grandpa's not being there. His not being there is a fact about the get together that makes it different; his absence gives the occasion a particular flavor and character of something being missing that is not adequately captured merely in the positive terms of a description of who is there and what they do.

We can say much the same about many situations in which there seems to be a definite identifiable presence of something by virtue of its absence, of the negative fact or state of affairs of its not being there. It is like an afterimage, in which the surroundings take on a different significance because of what has been subtracted. The nonoccurrence of fossils on Mars, if there happen to be no preserved plant or animal remains on its surface, a negative fact, is as much an important scientific discovery for remote explorers of the red planet as the positive finding of fossils would be, because of its value in helping to settle an outstanding question of extraterrestrial biology. The nonexistence of a proof or disproof of a mathematical theorem carries a similar kind of weight in the formal disciplines, especially with theorists and practitioners of an intuitionistic inclination. To give only a brief indication of some of the unlimitedly many further possibilities, we might think of the amputation of a limb and its separation from the body, independently of phantom limb experience, the removal of a cast from a broken arm, the sudden failure of the brakes on a speeding 
automobile, the departure of a troublesome co-worker, the loss of a loved one, the unexplained nonattendance of a scheduled speaker, the extraction of a tooth and its lack of contribution to a person's smile, and so on indefinitely.

A recent noteworthy and highly poignant example is the empty space in New York City where the twin towers of the World Trade Center stood before the terrorist attack of 11 September 2001. There, significantly, to commemorate the tragedy, a powerful set of vertically reaching lightbeams for some months afterward were used to outline the place that the buildings used to occupy. The fact, also, that many persons touched by the incident have thought it would be a more fitting tribute to the victims who lost their lives in the event never to build again a structure in the same place to replace the original towers also testifies to the meaning attached by some to the absence in that space where the buildings had been, a poignant presence in absence, and a negative state of affairs in which there continue to be no buildings like the ones that were destroyed.

If there are negative facts, then we may need to make reference to them in order to offer adequate characterizations of the state of the world. In that case, ontology and semantics must make provision for negative as well as positive states of affairs. Despite, but often precisely because of the fact that negative facts are states of affairs that do not exist, they make a unique addition to our understanding of the total condition of things, complementing our understanding of what exists with the significance of what also does not exist.

\section{Metaphysics of Holes and Interstitia}

Are holes and interstitia as empty, open or unoccupied spaces between existent things, themselves something positive, or are they negative states of affairs? Is the existence of a hole of whatever size or shape a fact or nonfact? If we think that the existence and quality of a hole is a positive state of affairs, then we must acknowledge that the filling of a hole is something negative, the absence or elimination of what had been a hole. This seems an odd, unnatural, and even backwards way of understanding the metaphysics of holes. Intuitively, it seems more plausible to regard a hole as an absence of solid physical stuff continuously surrounded by solid material substance, and hence as a negative state of affairs. ${ }^{7}$

Holes and interstitia as we ordinarily think of them are not altogether devoid of physical objects. An uncovered manhole in the street over a conduit leading to a sewer, or a

\footnotetext{
7 See Roberto Casati and Achille C. Varzi, Holes and Other Superficialities (Cambridge: The MIT Press (Bradford Books)).
}

mousehole chewed into the wainscoting, are good examples. The manhole and the mousehole within the Earth's atmosphere are filled from rim to rim with air molecules of varying compositions. The difference between solid and liquid or vaporous substance seems to be part of the analysis of the concept of a hole. The same is true of a hole in the ice within or beneath which the water of a lake or river remains fluid. It is a hole because the ice surrounding it is solid and the water filling the hole is not. A complete theory of the concept of holes is not yet in our grasp, because we have not settled on a set of intuitively satisfactory sufficient conditions for holes. We see this when we consider that a wine glass has a thin solid cylinder (or polygon) of solid material surrounding its opening and enclosing on the sides and bottom a generally nonsolid substance like air if the glass is empty or a liquid if the glass is in use. However, we would not ordinarily consider the solidly enclosed opening of a wine glass, aquarium, or the like, a receptacle to be filled, as a hole. A hole in such containers, properly so-called, would produce a leak, contrary to the vessel's intended purpose.

Whatever else a hole might be, we shall focus for the moment on what seems to be the necessary condition whereby a hole is something empty of solid material substance or at least of the same kind of solid material substance by which the hole is said to be surrounded. If a hole is essentially the absence of the same kind of (typically solid) material by which it is circumscribed, then the existence of a hole seems eminently to be a negative state of affairs. A 'hole' is a name for something that is not there, the absence of the same kind of thing, whatever it is, that surrounds the hole. The hole is an interruption in what would otherwise be the continuity of a material substance, and is therefore rightly described as an absence or lack of that otherwise uniform distribution of substance in a particular place. Some holes are natural, in which sense we rightly speak of body orifices as holes; others are caused, and are named either for their cause, as in the case of bullet holes, or for that with which they are meant to be filled, such as a buttonhole. Still other holes are named for the thing in which the hole occurs, such as a doughnut hole, a term also used popularly to refer to a nugget of dough about the size that would need to be removed from the center of a doughnut in order to create a round opening in a solid piece of dough, if, counterfactually, that was how doughnuts were made.

All holes and interstitia, properly so-called, are spaces where the distribution of a certain material is naturally, deliberately or accidentally missing or deleted. They are spaces in between the occurrence of physical stuff that are not filled with the same stuff, like a cavity in the enamel of a tooth. Such characterizations of holes and interstitia strongly suggest that their occurrences are negative states 
of affairs. They are what is not there in a certain place, in contrast with that which surrounds the opening. It is this sense of the word that seems to be relevant to metaphors and similes involving holes, such as the concept of a black hole in scientific cosmology. A black hole is not the absence of stuff, but rather the highly concentrated implosion of a star into a dwarf with a gravitational field so powerful that all matter in the vicinity, including all photons in light rays, are drawn and irretrievably compacted into its substance. A hole in the ground is ordinarily something that smaller objects can fall into, in much the same way that light rays literally fall into a black hole, never to return to open space. A black hole as such is after all a gap or lack or absence, despite being densely packed with matter, something missing in the fabric of space, namely, of light and the transmission of information by lightwave propagation into the morass of an enormous gravitational light sump.

If the existence of a hole or interstitium is literally a negative fact, constituting a lack or absence or discontinuity in the distribution of a certain material substance, then holes and interstitia like other kinds of absences can nevertheless be said to be something real, with a definite presence in absence. A hole can cause events to happen that would otherwise not occur. It can cause a toe to stick out of a stocking, milk to drip out of a carton, a jogger to fall and break an ankle, and many other things besides. A hole for oxygen to enter a closed compartment can save a life, while a hole in an aorta can kill. To say that there is a hole is to call attention to what is not there, what is not the case, even though grammatically we may speak of the existence of a hole along with its qualities and relations, as if it were something more positive. A hole can always be filled with something existent, the existence of which is a positive state of affairs, but the hole itself remains a negative fact, the absence of a certain kind of substance in a certain place. The sentence, therefore, that 'There is a hole in the table', according to the proposed ontic-semantic analysis, requires a negative state of affairs as its truthmaker, which also serves as the sentence's truth-breaker when in fact there is no hole.

\section{Conceivability of a Null Universe}

As a final application, we turn to the problems posed by the conceivability of a totally null universe. It appears intuitively possible for the universe to have contained nothing positive whatsoever, no material objects or their properties. If some form of radical nominalism turns out to be true, then there will be no abstract objects or their properties either, and hence no existent positive states of affairs at all.
There are difficulties in trying to think of an empty universe. If we imagine only a vast black space with no light and no planets or stars, then we will still be thinking of space, the existence of which might be regarded as something positive. We will also be including in the mental picture our own presence as thinkers 'observing' the emptiness with no lightwaves and no eyeballs or brains to process visual information, from a particular perspective and from a particular location in space. This is clearly a misleading way to try to conceive of a null universe, but, like many high level abstractions in physics and metaphysics, such as the occurrence of the Big Bang, relativity and quantum phenomena in four dimensions, and the like, it may be the best we can do as an intuitive aid to the understanding that we should nevertheless recognize as falling short of a proper representation. The idea that there might have existed nothing and hence no objects with any properties does not seem on first reflection to be logically inconsistent or self-contradictory. As such, it passes one of the frequently proposed tests for intelligibility as a logical possibility. The question then is how we are to understand the ontology and semantics of this (apparently) possibly true sentence considered in the abstract of a universe that is totally null and void. ${ }^{8}$

There may be more ingenious interpretations, but within a hybrid framework that incorporates both positive and negative states of affairs, it seems reasonable and arguably most natural to describe the null universe as a logically possible world in which the negative state of affairs exists in or by virtue of which there are no existent positive states of affairs. If we find it conceivable for the universe to be altogether lacking in any positive states of affairs, with no complex objects and hence no properties holding true of objects, or if we consider the problem of why there is something rather than nothing intelligible, regardless of how the question is to be satisfactorily answered, then we are presumably entertaining at least the logical possibility of there existing a global universal negative state of affairs in which there are no existent positive states of affairs. If such a negative state of affairs were to exist, occur, or obtain, then it would provide the negative factual truthmaker for the sentence considered in the abstract or projected as a mere logical possibility, that 'There is nothing rather than something', in the sense that there are supposed to be no existent positive states of affairs. We cannot accordingly dismiss such a possibility on purely logical grounds simply by resuscitating a version of the

\footnotetext{
${ }^{8}$ David Hume considers the inconceivability of a total vacuum in $A$ Treatise of Human Nature [1739-1740], edited by L.A. Selby-Bigge; second edition by P.H. Nidditch (Oxford: The Clarendon Press, 1978), pp. 55-59; 223. The argument is discussed in Dale Jacquette, "Hume on Infinite Divisibility and the Negative Idea of a Vacuum", The British Journal for the History of Philosophy, 10, 2002, pp. 413-435.
} 
Parmenidean-Platonic argument that even in that case there must exist the state of affairs by which there are no states of affairs, once we distinguish as proposed between positive and negative states of affairs, and once we allow negative states of affairs as truth-makers. ${ }^{9}$

If we are going to declare the impossibility of a null universe within a framework of positive and negative states of affairs, we can only do so through commitment to a substantive ontic thesis whereby the existence of at least some positive states of affairs is metaphysically guaranteed. If such an ontology can be upheld, it will follow that the negative state of affairs in which there are no existent positive states of affairs does not exist, occur, or obtain. Consequently, taking negative states of affairs as truth-breakers and sometime truth-makers into account, it is false that 'Nothing exists' and that 'There exist no positive states of affairs'. This will be so not merely as a result of the accidental existence of positive states of affairs as truth-breakers, but because of the doctrinally necessary existence of negative states of affairs as truth-breakers serving in this case to falsify the proposition that there are at least some contingently existent positive (physical) states of affairs. ${ }^{10,11}$

\footnotetext{
9 The so-called problem of being, of why there is something rather than nothing, was posed first by G.W. Leibniz in his essay, 'On the Ultimate Origination of Things' (1697), in Leibniz: Philosophical Writings, edited by G.H.R. Parkinson, translated by Mary Morris and Parkinson (London: J.M. Dent \& Son, 1973), pp. 136-144. More recently, the problem has been associated with the phenomenological ontology of Martin Heidegger and his obsession with 'the question of being'. See Heidegger, An Introduction to Metaphysics (Lectures 1953), translated by Ralph Manheim (New York: Doubleday, 1961), pp. $1-42$.
}

\footnotetext{
${ }^{10}$ Plato's Eleatic Stranger in his dialogue, the Sophist 237a-264b, offers this paradox. See Montgomery Furth, 'Elements of Eleatic Ontology', Journal of the History of Philosophy, 6, 1968, pp. 111132. Francis Jeffry Pelletier, Parmenides, Plato and the Semantics of Non-Being (Chicago: University of Chicago Press, 1990).

${ }^{11}$ A version of this essay was presented at the Society for Exact Philosophy, University of Toronto, Toronto, Canada, 19-22 May 2005, under the title 'Negative States of Affairs' as an invited lecture to the Vakgroep Theoretische Filosofie, Rijksuniversiteit Groningen, The Netherlands, 2 November 2005, and in revised form as 'Logic and Semantics of False Predications' at the Universität Salzburg, Austria, 18 May 2006. I recall with fondness the warm reception I enjoyed at Salzburg from my friends and critics, Edgar Morscher, Paul Weingartner, Alexander Heike, Arkadiusz Chrudzimski, and the graduate students and other attendees of my Oberseminar with Morscher on 'Philosophische Logik', 15-19 May 2006. Special thanks are due to Theo A.F. Kuipers and Erik W. Krabbe for thoughtprovoking comments at the Groningen colloquium. I am grateful to the Netherlands Institute for Advanced Study in the Humanities and Social Sciences (NIAS), Royal Netherlands Academy of Arts and Sciences (KNAW), for support of this and related topics in philosophical logic and philosophy of mathematics during my visit as Resident Research Fellow in 2005-2006. Later incarnations appeared under the title 'On the Logic of Negation', Department of Philosophy, University of Aberdeen, Scotland, 20 February 2007, and 'Logic and Metaphysics of Negative States of Affairs', presented to the Department of Philosophy, Bilkent University, Ankara, Turkey, 24 April 2007.
} 